\title{
Effect of zeolite morphology on separated charge states: ZSM-5-type nanocrystals, nanosheets and nanosponges
}

Lucie Duplouy $^{\mathrm{a}}$, Alain Moissette ${ }^{\mathrm{a}}$, Matthieu Hureau $^{\mathrm{a}}$, Vincent De Waele ${ }^{\mathrm{a}}$, T. Jean Daou ${ }^{\mathrm{b}, \mathrm{c}}$, Isabelle Batonneau-Gener ${ }^{\mathrm{d}}$

${ }^{a}$ LASIRE, Bât. C5, Faculté des Sciences et Technologies, Université de Lille, 59655 Villeneuve d'Ascq cedex, France

${ }^{\mathrm{b}}$ Université de Haute Alsace (UHA), CNRS, IS2M (Institut de Science des Matériaux de Mulhouse, UMR 7361, F-68100 Mulhouse, France

${ }^{\mathrm{c}}$ Université de Strasbourg, France

${ }^{\mathrm{d}}$ IC2MP, Université de Poitiers, Poitiers 86073, France.

\begin{abstract}
In the present work, we investigate the electron transfers occurring in the porous void of three MFI-type zeolites (ZSM-5) nanomaterials (nanocrystals, nanosheets and nanosponges) after adsorption and photoexcitation of t-stilbene (t-St). ZSM-5 nanosheets are constituted of lamellar stacking of several nanosheets $(20-40 \mathrm{~nm})$ where each nanosheet have a thickness of $2 \mathrm{~nm}$. Nanosponges are composed of ZSM-5 nanocrystals (2-3 nm) separated by mesoporous holes of $5.8 \mathrm{~nm}$ in such a way to obtain hierachical materials. While the nanosheets show a microporosity similar to that observed for ZSM-5 nanocrystals, the absorption isotherms of the nanosponges show the existence of a secondary microporosity. After photoirradiation of t-St, UV-vis absorption spectroscopy shows the formation of charge separated states (Radical Cation and Charge Transfer Complex) in the nanocrystals and in the nanosheets whereas no ionized species is detected in the nanosponges. Radical Cation (RC) is stabilized in nanosheets while it evolves very rapidly towards a Charge Transfer Complex (CTC) in nanocrocrystals. The particular morphology of the nanosheets and nanosponges is put forward to explain this result since all host materials are of MFI-type. To investigate ultra-short phenomena in the three nanomaterials, UV-vis transient spectra were recorded between 2 and $450 \mu \mathrm{s}$ after photoexcitation by nanosecond laser pulses. In nanocrystals and nanosheets only the RC is detected whereas CTC formation is not observed. Photoexcitation of t-St in nanosponges also leads to the formation of $\mathrm{RC}$ but it recombines completely within $70 \mu \mathrm{s}$. This suggests the preferential location of $\mathrm{t}$-St in the secondary microporosity with pores larger than the micropores of the MFI-type framework and possibly in the mesopores of the nanosponge.
\end{abstract}

\section{Introduction}

The capacity of zeolites to stabilize long-lived charge separated states (CSS) that are formed upon (or following) the ionization of confined guest molecules is an intrinsic property of the 
inner surface of the microporous volume ${ }^{1-22}$. Indeed, the host guest interactions make it possible to modulate the reactivity of the adsorbed molecule and constitute the real driving force of the reaction processes. Besides the nature of the molecule, the aluminium content, the pore dimension, the nature of the charge balancing cation, ... have been clearly identified as parameters that govern the ionization efficiency and the rate of the recombination of charges. ${ }^{23,24}$ However, the chemical composition of zeolites alone cannot explain the formation and stabilization of radical species in their pores and the microporous morphology of the material must also be considered. ${ }^{25}$

Zeolites are widely used in fields such as adsorption, catalysis and optoelectronics but certain applications are limited due to low adsorption capacities or slow adsorption kinetics. One solution to improve the performance of the porous materials is to use nano-sized particles and introduce additional mesoporosity within or between zeolite crystals to reduce the diffusion path and enhance adsorption capacities. ${ }^{26-31}$ In particular, the creation of secondary mesoporosity is interesting as it minimizes negative effects, such as pore blockage and coke formation in catalysis. In these hierarchical nano-sized zeolites, the presence of short microporous channels and large external surface area are two key factors that can improve the activity and selectivity of these materials..$^{32,33,34}$ In that context of emergence of new zeolitetype materials such as hierarchical zeolites it appears very important to identify the influence of the morphology on the formation and evolution of CSS. ${ }^{25,35,36,37,38}$

MFI-type zeolite is particularly interesting due to its three-dimensional channel system with 10-membered ring (MR) openings $(0.55-0.56 \mathrm{~nm})$. Thanks to new synthesis methods, ${ }^{27-30,39-43}$ it is now possible to control the morphology of zeolites to eventually make their properties "tunable" not only by preparing materials in the form of microcrystals but also with more complex architectures. The purpose of this work is to determine whether the different declinations of this morphology can have an impact on the reactivity and stabilization of the separate charge states. Toward this end, we report the electron transfers occurring after photoexcitation of $\mathrm{t}$-stilbene $(\mathrm{t}-\mathrm{St})$ incorporated in three different morphologies of the ZSM-5 structure synthesized in the form of nanocrystals, nanosheets and nanosponges. The stacking of ZSM-5 nanosheets with a thickness of $2 \mathrm{~nm}$ constitutes a lamellar structure, whereas nanosponges are composed of ZSM-5 nanocrystals $(2-3 \mathrm{~nm})$ separated by mesoporous holes of $5.8 \mathrm{~nm}$ organized in such a way to create hierachical materials The photoinduced electron transfers processes in t-St containing ZSM-5 are investigated on a time scale ranging from $\mu \mathrm{s}$ to several hours by using steady state and time resolved diffuse reflectance spectroscopy. 


\section{Experimental}

\section{Synthesis of nanomaterials of MFI-type structure}

Nanocrystals. ZSM-5 nanocrystals $0.1 \mu \mathrm{m}$ size were hydrothermally synthesized using tetrapropylammonium ions as structuring agents. Tetrapropylammonium hydroxide (TPAOH) is dissolved in distilled water and mixed with $\mathrm{NaAlO}_{2}$ at room temperature for 15 minutes. Then, tetraethylorthosilicate (TEOS) is added to the drip under magnetic agitation. The gel formed is composed of $1.00 \mathrm{SiO}_{2}: 0.05 \mathrm{NaAlO}_{2}: 0.38 \mathrm{TPAOH}: 17 \mathrm{H}_{2} \mathrm{O} .{ }^{31}$ This gel is kept under stirring for one hour at room temperature, then 3 hours at $100{ }^{\circ} \mathrm{C}$. The curing phase of the gel is 20 hours under stirring at room temperature. The mixture is transferred to an autoclave and placed in the oven for 48 hours at $180^{\circ} \mathrm{C}$. Once cooled, the suspension is centrifuged and washed with demineralized water. The samples described above are then dried overnight at $100^{\circ} \mathrm{C}$ and calcined in air for 5 hours at $550^{\circ} \mathrm{C}$.

Nanosheets. The synthesis process is characterized by the use of structuring molecules that block the growth of crystals along the $\mathrm{b}$ axis (straight channel). Since the crystals develop only along the a and c axes, the product obtained is thus in the form of zeolite nanosheets. The structuring molecule used here is a di-quaternary ammonium surfactant cation: $\mathrm{C}_{22} \mathrm{H}_{45}$ $\mathrm{N}^{+}\left(\mathrm{CH}_{3}\right)_{2}-\mathrm{C}_{6} \mathrm{H}_{12}-\mathrm{N}^{+}\left(\mathrm{CH}_{3}\right)_{2}-\mathrm{C}_{6} \mathrm{H}_{13}$ (noted $\left.\mathrm{C}_{22-6-6}\right){ }^{39}$

The synthesis of nanosheets was carried out according to the Choi et al. protocol. ${ }^{39}$ Typically, $0.24 \mathrm{~g}$ of sodium hydroxide (Riedel de Haën, 99\%) and $0.062 \mathrm{~g}$ of aluminium sulphate (rectapur, 99\%) were added in a Teflon@ $45 \mathrm{ml}$ jacket, then solubilised in $7.17 \mathrm{~g}$ of demineralised water. $0.73 \mathrm{~g}$ of $\mathrm{C}_{22-6-6}$ and $0.18 \mathrm{~g}$ of sulphuric acid (Aldrich), were then added under magnetic agitation. After homogenization, $2.13 \mathrm{~g}$ of tetraethoxysilane (TEOS, Aldrich, 98\%) was added. The gel was magnetically stirred to obtain a viscous and milky solution of a molar composition: $1 \mathrm{SiO}_{2}: 0.01 \mathrm{Al}_{2} \mathrm{O}_{3}: 0.3 \mathrm{Na}_{2} \mathrm{O}: 0.18 \mathrm{H}_{2} \mathrm{SO}_{4}: 0.1 \mathrm{C}_{22-6-6-6}: 40 \mathrm{H}_{2} \mathrm{O}$. The gel was stirred at $1000 \mathrm{rpm}$ for 4 hours at $60^{\circ} \mathrm{C}$. The liner was placed in its original autoclave, itself placed in hydrothermal condition at $150^{\circ} \mathrm{C}$ for 5 days in an oven equipped with a mechanical stirring system of "spindle turn" type allowing the reaction mixture to be stirred at a speed of $30 \mathrm{rpm}$. After synthesis, the product was filtered, washed in demineralized water and dried overnight at $100^{\circ} \mathrm{C}$. The bifunctional agent was then eliminated by calcination at $550^{\circ} \mathrm{C}$ for 8 hours under air.

Nanosponges. The synthesis of ZSM-5 nanosponges was performed according to the Na et al. 40 protocol where the texturing and structuring agent is $\mathrm{C}_{18}$ $\mathrm{N}\left(\mathrm{C}_{1}\right)_{2} \mathrm{C}_{6} \mathrm{~N}(\mathrm{C} 1)_{2} \mathrm{C}_{6} \mathrm{~N}\left(\mathrm{C}_{1}\right)_{2} \mathrm{C}_{6} \mathrm{~N}\left(\mathrm{C}_{1}\right)_{2} \mathrm{C}_{18}$ designated by $\mathrm{C}_{18-6-6} \mathrm{C}_{18}$. In a $45 \mathrm{ml}$ Teflon@ liner, 0.073 $\mathrm{g}$ of sodium aluminate (Strem Chemical, $39.5 \%$ by weight $\mathrm{Na}_{2} \mathrm{O} ; 56.7 \%$ by weight $\mathrm{Al}_{2} \mathrm{O}_{3} ; 3.3 \%$ 
by weight $\mathrm{H}_{2} \mathrm{O}$ ), and $0.26 \mathrm{~g}$ of $\mathrm{NaOH}$ (Riedel de Haën, 99\%) were homogenized in $21.31 \mathrm{~g}$ of demineralized water. Then $3.54 \mathrm{~g}$ of tetraethoxysilane (TEOS, Aldrich, 98\%) and $3.06 \mathrm{~g}$ of ethanol were added to the reaction medium to form a solution of molar composition: $1 \mathrm{SiO}_{2}$ : $0.025 \mathrm{Al}_{2} \mathrm{O}_{3}: 0.2 \mathrm{Na}_{2} \mathrm{O}: 8 \mathrm{ETOH}: 0.05 \mathrm{C}_{18-6-6} \mathrm{C}_{18}: 71 \mathrm{H}_{2} \mathrm{O}$. The solution was stirred for 6 hours at $60^{\circ} \mathrm{C}$. The liner was placed in the autoclave and the assembly was heated to $150^{\circ} \mathrm{C}$ for 5 days in an oven equipped with a mechanical stirring system of the "spindle turn" type allowing the reaction mixture to be stirred at a speed of $30 \mathrm{rpm}$. After synthesis, the product was filtered, washed with demineralized water and dried overnight at $100^{\circ} \mathrm{C}$. The structuring agent was removed by calcination at $550^{\circ} \mathrm{C}$ for 8 hours under air. The nanosponges possess spiky morphology and are composed of ZSM-5 nanocrystals separated by mesoporous walls in such a way to obtain hierarchical materials containing micropores and mesopores.

\section{Cation exchange of MFI-type structure.}

The three ZSM-5 zeolite samples were $\mathrm{Na}^{+}$-ion-exchanged $\left(\mathrm{H}^{+}\right.$to $\mathrm{Na}^{+}$cation exchange) with a $1 \mathrm{M} \mathrm{NaCl}$ aqueous solution heated at $50^{\circ} \mathrm{C}$ during $5 \mathrm{~h}$. Typically, $1 \mathrm{~g}$ of zeolite ZSM-5 is soaked in $25 \mathrm{~mL}$ of this $\mathrm{NaCl}$ solution. The ion exchange process was repeated five times for all samples.

\section{Adsorption procedure.}

All $\mathrm{Na}^{+}$containing zeolite samples were heated up to $450^{\circ} \mathrm{C}$ under Ar. Then, the dehydrated zeolites were cooled to room temperature under dry argon. Weighed amounts of t-stilbene (t$\mathrm{St}, \mathrm{C}_{14} \mathrm{H}_{12}$, Merck-Schuchardt) corresponding to $0.5 \mathrm{t}-\mathrm{St} / \mathrm{Unit}$ Cell were introduced into the cell under dry argon and the powder mixture was shaken. The powders were transferred under dry argon in a quartz glass Suprasil cell for spectral experiments. The samples were stocked in the dark at room temperature until complete sorption.

\section{Characterization techniques}

Electron microscopy. Homogeneity and morphology of the produced crystals were examined by $7 \mathrm{kV}$ accelerating voltage scanning electron microscopy (SEM) (Philips XL 30 FEG microscope) and a transmission electron microscope (TEM) (Philips model CM200), working with a $0.3 \mathrm{~nm}$ point-to-point resolution, at $200 \mathrm{kV}$.

Sorption isotherms. Surface area and microporous volume of the produced zeolites were determined by $\mathrm{N}_{2}$ sorption (ASAP 2420 system, Micromeritics, USA) and calculated adopting t-plot and BET processes. BJH method was used to calculate the mesoporous volume. Prior to single measures, $50 \mathrm{mg}$ of the zeolite samples were outgassed for $15 \mathrm{~h}$, at $300{ }^{\circ} \mathrm{C}$. Measurements of nitrogen sorption were carried out at $-196{ }^{\circ} \mathrm{C}$. 
X-Ray Diffraction. A PANalytical MPD X'Pert Pro diffractometer equipped with an $\mathrm{X}^{\prime}$ Celerator real-time multi-strip detector (2.122 $2 \theta$ active length) and operating with $\mathrm{Cu} \mathrm{K}_{\alpha}$ radiation $(\lambda=0.15418 \mathrm{~nm}$ ) was used to obtain the X-ray diffraction patterns and purity of the produced zeolite materials. The zeolite's diffractogram was recorded at $22{ }^{\circ} \mathrm{C}$ in the low range 0.5 $<2 \theta<5^{\circ}$ and wide range $3<2 \theta<50^{\circ}$ (220 sec time step and $0.017^{\circ} 2 \theta$ angle step).

Elementary analyses. The global Si/Al ratios of the produced samples were determined by Xray fluorescence spectroscopy (XRF) (Philips, Magic X). These results were then coupled with \% of $\mathrm{Al}$ extraframework determined from ${ }^{27} \mathrm{Al}$ NMR spectra of the samples (see Figure S2) to obtain Si/Al of the ZSM-5 framework. XRF was also used to evaluate the successful cation exchange. ${ }^{27} \mathrm{Al}(\mathrm{I}=5 / 2)$ magic angle spinning (MAS) NMR was carried out with a Bruker Avance II 400 spectrometer operating at $\mathrm{B}_{0}=9.4 \mathrm{~T}$ (Larmor frequency $v_{0}=104.2 \mathrm{MHz}$ ) equipped with a Bruker $2.5 \mathrm{~mm}$ double channel probe. The rotor was spun at $25 \mathrm{kHz}$, and free induction decays (FID) were collected with a p/12 rf pulse $(0.6 \mathrm{~ms})$ and a recycle delay of $1 \mathrm{~s}$. Measurements were carried out with $\left[\mathrm{Al}\left(\mathrm{H}_{2} \mathrm{O}\right)_{6}\right]^{3+}$ as external standard reference. ${ }^{32}$ The decompositions of the spectra were performed using the DMFit software. ${ }^{44}$

Acidity: Pyridine adsorption trailed by infrared spectrometry in a Thermo Nicolet Magna 550FT-IR spectrometer were used to measure the amount of Lewis and Brønsted acid sites. Samples of zeolite were squeezed into self-supported pellets of $20 \mathrm{mg}$. Each wafer was then preheated at $450{ }^{\circ} \mathrm{C}$ in an analysis cell for $12 \mathrm{~h}$, in air. The cell was later placed under vacuum for $1 \mathrm{~h}$ to remove physisorbed molecules after decreasing the wafer temperature to $200{ }^{\circ} \mathrm{C}$. Prior to introducing pyridine in the cell for $5 \mathrm{~min}$, the temperature was further reduced to $150{ }^{\circ} \mathrm{C}$. The amounts of Brønsted $\left[\mathrm{PyrH}^{+}\right]$and Lewis $[\mathrm{PyrL}]$ acid sites were established using extinction coefficients previously determined by Guisnet et al., ${ }^{45}$ following integrating peak areas at $1545 \mathrm{~cm}^{-1}$ and $1454 \mathrm{~cm}^{-1}$ respectively.

Diffuse Reflectance UV-vis spectroscopy (DRUVv). The progressive incorporation of t-St was monitored as a function of time by conventional diffuse reflectance UV-visible absorption spectroscopy. The absorption spectra were recorded between 200 and $1800 \mathrm{~nm}$ using a Cary 6000 spectrometer. The instrument was equipped with an integrating sphere to study the powdered zeolite samples through diffuse reflectance; the corresponding bare zeolite was used as the reference. The DRUVv spectra were plotted as the Kubelka-Munk function.

Time Resolved Diffuse Reflectance UV-vis spectroscopy (TRDRUVv). The excitation beam $\left(\lambda_{\text {ex }}=300 \mathrm{~nm}\right)$ is delivered by an optical parametric oscillator (OPO) injected by a nanosecond Nd:YAG laser. It delivers pulses of $5 \mathrm{~ns}$, at a rate of $10 \mathrm{~Hz}$. The pump energy on the sample was $1 \mathrm{~mJ}$. The transient absorption was measured by using a $150 \mathrm{~W}$ pulsed Xe lamp (Applied 
Photophysics). The scattered white light is collected at about $67^{\circ}$ to the normal of the sample surface and focused on the entrance slit of a monochromator. The excitation beam forms an angle of approximately $27^{\circ}$ with the entrance face of the sample cell to avoid collecting specular reflection. At the output of the monochromator, the signal is detected using a photomultiplier tube (PMT) sampled using a digital oscilloscope (LeCroy). The decays are averaged over 4 32 shots, depending on the wavelength. The sample is manually stirred between measurements to renew the photo-irradiated area.

Raman scattering. Raman spectra were recorded using a near-IR FT-Raman spectrometer (Bruker RFS $100 / \mathrm{S}$ instrument) with a CW Nd:YAG laser $\left(\lambda_{\mathrm{ex}}=1064 \mathrm{~nm}\right)$ as an excitation source. A laser power of 10-100 $\mathrm{mW}$ was used. The spectra were measured in the region 150$4000 \mathrm{~cm}^{-1}$ with a resolution of $2 \mathrm{~cm}^{-1}$ and were accumulated over 1000 scans.

Kinetic calculations. The charge recombination kinetic was analysed through the $\mathrm{C}(\mathrm{t})$ decay. The concentration decays $\mathrm{C}(\mathrm{t}) / \mathrm{C}_{0}$ were fitted using the Albery function that takes into account the heterogeneity of the material. ${ }^{46}$

\section{Results}

\section{Physico-chemical properties of nanomaterials of MFI-type structure}

The $100 \mathrm{~nm}$ nanocrystals show pseudospherical particles with poor defined contours, (Figure 1). For nanosheets, the use of the bifunctional compound $C_{22-6-6-6}$ in place of the conventional structuring agent TPAOH leads to the formation of lamellar nanosheets by preventing growth in the direction $b$. The stacking of sheets thus formed have a thickness varying between 20 and $40 \mathrm{~nm}$ and their assembly shows a morphology of the "sand rose" type (Figure 1). The thickness of each of these nanosheets is $2 \mathrm{~nm}$ along the $\mathrm{b}$ axis, which corresponds to one unit cell. The straight channel is then also $2 \mathrm{~nm}$ long. Mesostructured nanosponges obtained with another structuring agent, $\mathrm{C}_{18-6-6} \mathrm{C}_{18}$, possess a spiky morphology with an average length between 250 and $350 \mathrm{~nm}$ (Figure 1). This spiky morphology is composed of ZSM-5 nanocrystals interconnected together in the presence of mesoporous walls.

Sorption isotherms. The nanocrystals have a type I+II isotherm characteristic of microporous materials with nanometric particles ${ }^{47}$ Figure 2. The significant rise in adsorbed volume at high $\mathrm{p} / \mathrm{p}^{0}$ values is due to the filling of the intergranular mesoporosity. The values of the micro and mesoporous volumes determined during the $\mathrm{N}_{2}$ sorption are summarized in Table 1. Note that the calculated mesoporous volumes correspond to intergranular volumes since the samples are 
perfectly microporous. The values of the specific surface areas of the material calculated using BET $^{48}$ equation are presented in Table 1.

For nanosheets, a type I isotherm is observed at low pressure $\mathrm{p} / \mathrm{p}^{0}$ with a microporous volume of $0.18 \mathrm{~cm}^{3} \cdot \mathrm{g}^{-1}$ and a type IIb isotherm at high pressure. The hysteresis observed between $0.4<\mathrm{p} / \mathrm{p}^{0}<1$ is due to the stacking of nanosheet and is characteristic of lamellar materials. For nanosponges, the graph shows a type Ib isotherm at low pressure $\mathrm{p} / \mathrm{p}^{0}\left(\mathrm{~V}_{\text {micro }}\right.$ of $\left.0.30 \mathrm{~cm}^{3} \cdot \mathrm{g}^{-1}\right)$ while at high pressure, a type II and IV isotherm is observed showing the presence of interparticle mesoporosity. ${ }^{31,49}$ These results show a significant increase in microporous volume for nanosponges due to the existence of secondary microporosity. Indeed, the total pore volume and BET surface area increase for hierarchical materials. All the values derived from isotherms concerning the textural properties of the three morphologies are grouped together in Table 1.

Table 1: Textural parameters and amount of acid sites in the nanomaterials

\begin{tabular}{l|ccc|cccc}
\hline \multicolumn{1}{|c|}{} & \multicolumn{5}{c}{ Porosity } \\
\hline Samples & $\mathrm{Si} / \mathrm{Al}_{\text {global }}$ & $\mathrm{Si} /$ Al framework & $\mathrm{EFAL}(\%)$ & $\mathrm{V}_{\text {total }}\left(\mathrm{cm}^{3} \cdot \mathrm{g}^{-1}\right)$ & $\mathrm{V}_{\text {micro }}\left(\mathrm{cm}^{3} \cdot \mathrm{g}^{-1}\right)$ & $\mathrm{V}_{\text {meso }}\left(\mathrm{cm}^{3} \cdot \mathrm{g}^{-1}\right)$ & $\mathrm{S}_{\mathrm{BET}}\left(\mathrm{m}^{2} \cdot \mathrm{g}^{-1}\right)$ \\
\hline nanocrystals & 29.7 & 31 & 1 & 0.33 & 0.16 & 0.169 & 382 \\
nanosheets & 44 & 55 & 20 & 0.54 & 0.18 & 0.36 & 492 \\
nanosponges & 23 & 33 & 30 & 1.28 & 0.3 & 0.78 & 888 \\
\hline
\end{tabular}

\begin{tabular}{|c|c|}
\hline & Acidity \\
\hline Samples & Lewis $\left(150^{\circ} \mathrm{C}\right)\left(\mu \mathrm{mol} \mathrm{g}{ }^{-1}\right)$ \\
\hline nanocrystals & 50 \\
\hline nanosheets & 80 \\
\hline nanosponges & 103 \\
\hline
\end{tabular}

X-Ray Diffraction. The diffractograms obtained for the nanocrystals show the presence of a single MFI-type phase without amorphous phase. Nevertheless, a slight shift from peaks to wide angles is observed and can be explained by a smaller amount of aluminum within the structure. ${ }^{50}$ Diffractograms recorded at room temperature for nanosheets synthesized in the presence of the bifunctional compound $\mathrm{C}_{22-6-6-6}$ before and after calcination are characteristic of multilamellar MFI (Figure S1). Indeed, if there is a certain degree of mesostructuration before calcination, the diffraction peaks due to this phenomenon disappear after calcination while the 
peaks relating to crystallographic planes (h0l) are present on the diffractogram of the nanosheets confirming the growth inhibition along the b-axis. The X-ray diffractogram obtained for nanosponges shows a mesostructuration which is characterized in particular by a wider peak at low angles. The reflections observed in the wide angle range are also attributed to a 2D hexagonal symmetry comparable to that of organized mesoporous silica of the MCM-41 type. Unfortunately, due to their small crystal size, peaks cannot be well resolved. (Figure S1)

Elementary analyses. The $\mathrm{Si} / \mathrm{Al}_{\text {framework }}$ vary from one morphology to another and are found to be 31,55 and 33 for nanocrystals, nanosheets and nanosponges, respectively, Table 1.

\section{Adsorption of t-St in ZSM-5 nanocrystals, nanosheets and nanosponges}

After mixing the t-St molecules with ZSM-5 crystals of different morphologies (nanocrystals, nanosheets and nanosponges types), the evolution of the samples was monitored over time by diffuse reflection UV-visible absorption spectroscopy. The graphs show an increase of the absorption band at 300-310 $\mathrm{nm}$ that was already assigned to the diffusion of t-St molecules to their adsorption sites. ${ }^{22}$ It should be noted that it has been demonstrated in previous studies, both experimental and theoretical, that guest molecules such as t-stilbene preferentially adsorb in sites where they interact with extra-framework cations within straight channels. ${ }^{22,51} \mathrm{Six}$ months after the mixing, the intensities at $310 \mathrm{~nm}$ did not evolve anymore which is characteristic of samples at equilibrium, Figure S3. The analysis of the samples was also performed by FT-Raman spectroscopy (Figure 3). The spectra all exhibit the presence of the $1639 \mathrm{~cm}^{-1}$ line characteristic of the neutral molecule showing that $\mathrm{t}-\mathrm{St}$ is not ionized within the porous network. In order to generate CSS, the samples were irradiated at $\lambda_{\mathrm{ex}}=300 \mathrm{~nm}$ corresponding to the absorption band of t-St to photoinitiate the ionization of the guest molecules.

DRUVv (nanocrystals). After photoexcitation at $300 \mathrm{~nm}\left(30 \mathrm{~mJ} / \mathrm{cm}^{2}\right)$ for 30 seconds, the diffuse reflection UV-vis spectra were recorded between $5 \mathrm{~min}$ and more than 24 hours to monitor the charge transfer reaction mechanisms involved after ionization (Figure 4). The first spectra obtained immediately after excitation of t-St incorporated in ZSM-5 nanocrystals show the appearance of new bands at $475 \mathrm{~nm}$ and at 565 and $620 \mathrm{~nm}$ in the visible range and a very broad band around 1200-1500 $\mathrm{nm}$ in addition to the band centred around $300 \mathrm{~nm}$ assigned to the adsorbed molecular t-St. The band observed at $475 \mathrm{~nm}$ is attributed to the cation radical $\mathrm{t}-$ $\mathrm{St}^{\bullet+} 22,52,53$ formed after the photoionization of $\mathrm{t}-\mathrm{St}$ and the ejection of an electron which is trapped in the framework as follows: 


$$
\mathrm{t}-\mathrm{St} @ \mathrm{HZSM}-5+\mathrm{h} v \rightarrow \mathrm{t}-\mathrm{St}^{\bullet+} @ \mathrm{HZSM}-5^{\bullet-} \text { (Eq.1) }
$$

The bands at 565 and $620 \mathrm{~nm}$ are characteristic of a charge transfer complex (CTC) formed by the non-direct recombination of the radical cation which takes place by the capture of another electron from a zeolite donor site according to: ${ }^{22}$

\section{$\mathrm{t}-\mathrm{St}^{\bullet+} @ \mathrm{HZSM}-5^{\bullet-} \rightarrow \mathrm{t}-\mathrm{St} @ \mathrm{HZSM}-5^{\bullet-\bullet+}$ (Eq. 2)}

The neutral molecule in strong interaction with the positive hole created during the recombination of radical cation constitutes the charge transfer complex which is characterized by the broad band in the visible range. The broad band observed in the near-IR region is characteristic of the spectral signature of the unpaired electrons. The evolution of these bands corresponds to the reaction mechanism described in previous work to explain the electron transfers occurring after photoionization of a molecule adsorbed in a ZSM-5 type zeolite. ${ }^{22}$ It is important to precise that unfortunately, we are not able to determine and discuss the nature of the initial excited states in these porous environments since we don't have access to processes shorter than $\mu \mathrm{s}$ for these solid samples. Nevertheless, note that the formation of $t$-stilbene radical cation in acetonitrile solution was reported after laser flash photolysis (266 or $355 \mathrm{~nm}$ ). The formation of $\mathrm{t}_{-} \mathrm{St}^{\bullet+}$ was explained by two-step two-photon excitation from the ground state $\left(S_{0}\right)$ to the lowest singlet excited state $\left(S_{1}\right)$ and from the $S_{1}$ (ps time scale) to the higher singlet excited state $\left(\mathrm{S}_{\mathrm{n}}\right)$, from which ionization occurs. ${ }^{54}$

The recombination kinetics of RC and CTC are presented in Figure 5 and the values of the rate and lifetime constants are calculated using the Albery model ${ }^{46}$ adapted to the heterogeneity of porous systems are shown in Table 2. The present results show the same reaction mechanism and similar lifetime values for the $\mathrm{RC}(\tau=16 \mathrm{~min})$ and for the $\mathrm{CTC}(\tau=233 \mathrm{~min})$ as previously reported for microcrystals $2 \mu \mathrm{m}$ size with $\mathrm{Si} / \mathrm{Al}=27 .{ }^{22}$

DRUVv nanosheets. The UV-vis absorption spectra obtained after photoexcitation of the adsorbed t-St in nanosheets are shown in Figure 4. New bands of relatively low intensity are observed in the visible range and correspond to the characteristic bands of RC and CTC, respectively. The decays of the band assigned to RC and CTC were plotted together with the fit by using the Albery model (Figure 5). The rate constants and lifetime values reported in Table 2 show that, contrary to what is observed for nanocrystals, the lifetime of the cation radical, $\tau$ $=95 \mathrm{~min}$, is longer than that of the CTC, $\tau=70 \mathrm{~min}$. These values indicate that, in ZSM-5 nanosheets, the cation radical is the most stable species and its lifetime is significantly longer 
than for the nanocrystals. Although charge transfer to form the CTC is observed, this reaction does not appear to be favoured and the species is poorly stabilized compared to what is observed here for ZSM-5 nanocrystals and for microcrystals as observed in previous studies. ${ }^{22}$

DRUVv Nanosponges. After photoexcitation of the t-Stilbene adsorbed in the ZSM-5 nanosponges, the sample evolution was followed by UV-vis absorption spectroscopy in diffuse reflection. The spectra recorded 5 minutes after irradiation show no change in the spectrum (Figure 4). However, since the presence of t-stilbene has been demonstrated within the porous nanosponge framework of ZSM-5 by Raman spectroscopy, this result indicates that no longlived charge species are photogenerated.

Table 2: Lifetimes and kinetic constants for the radical cation (RC) and for the charge transfer complex (CTC) obtained using diffuse reflectance UV-vis (DRUVv) and time resolved diffuse reflectance UV-vis (TRDRUVv) spectroscopies.

\begin{tabular}{l|cccc|ccc}
\cline { 2 - 8 } & \multicolumn{5}{c|}{ DRUVV } & \multicolumn{3}{c}{ TRDRUVV } \\
\cline { 2 - 8 } & $\mathrm{RC}$ & $\mathrm{CTC}$ & $\mathrm{RC}$ & $\mathrm{CTC}$ & $\mathrm{RC}$ & $\mathrm{CTC}$ & $\mathrm{RC}$ \\
\hline Samples & $\tau(\mathrm{min})$ & $\tau(\mathrm{min})$ & $\mathrm{k}\left(\mathrm{min}^{-1}\right)$ & $\mathrm{k}\left(\mathrm{min}^{-1}\right)$ & $\tau(\mu \mathrm{s})$ & $\tau(\mu \mathrm{s})$ & $\mathrm{k}\left(\mu \mathrm{s}^{-1}\right)$ \\
\hline nanocrystals & 24 & 96 & 0.0412 & 0.0050 & 600 & - & 0.00167 \\
nanosheets & 200 & 70 & 0.0105 & 0.0142 & 134 & - & 0.00746 \\
nanosponges & - & - & - & - & 70 & - & 0.01429 \\
\hline
\end{tabular}

TRDRUVv (nanocrystals). In order to better characterize the electron transfer processes after photoexcitation, we performed nano-to ms time-resolved UV-vis spectroscopy. The graph presented in figure 6 shows the transient spectra reconstructed for several delays between $3 \mu \mathrm{s}$ and $450 \mu$ s after the photoexcitation of the sample. The spectra show only the contributions of the cation radical characterized by the strong absorption band centred at $475 \mathrm{~nm}$ and by a smaller contribution around $700 \mathrm{~nm}$. No band ascribable to CTC is observed between 500 and $650 \mathrm{~nm}$. These results reveal the fact that the creation of the CTC is a slow process taking place in the s-min time scale. This suggests that the ejected electron, before being trapped, must probably first relocate within the zeolite according to the principle of compartmentalization of charges. ${ }^{55,56}$ It follows an oxidation of the zeolite by the t-St cation to form a positive hole and the CTC.

We can notice that the transient spectra in Figure 6 show however a small decrease in the contribution of the cation radical with the time. This decrease corresponds to the direct recombination of the $\mathrm{t}-\mathrm{St}$ cation radical, with the stabilized electrons. The modelling of the 
kinetics of the decay of the cation radical was performed using the Albery model and is presented in Figure 7. The graph shows that the decay reaches a horizontal asymptotic value well above zero, indicating only partial recombination of the cation radical. The value of this asymptote $\left(\mathrm{y}_{0}>0.4\right)$, estimated by extrapolation using the Albery model, indicates that more than $40 \%$ of the photogenerated cation radicals do not recombine directly within the first 500 $\mu$ s (Table 2). The stabilization of a large proportion of the cation radical for durations longer than ms therefore demonstrates that there is no competition between the direct recombination occurring in very short time (less than ms) and possible electron transfer occurring at much longer times. The lifetime of the cation radical $(600 \mu \mathrm{s})$ calculated by the Albery method is attributed to direct recombination. It is interesting to note that this value is in the same range as the one determined after ionization of t-St in silicalite-1 $(\tau=1200 \mu \mathrm{s})$, the structural analogue of ZSM-5 without aluminum, where t-St recombines exclusively directly since the delocalization of electrons in the framework cannot take place without $\mathrm{Al}^{22}$

TRDRUVv nanosheets. The spectra recorded after the excitation of adsorbed $t-S t$ in nanosheets are shown in Figure 6. The spectra and their evolution are similar to those obtained previously for the nanocrystals. We only find the contributions of the cation radical and the electronic hole transfer leading to the formation of the CTC is not observed on this time scale. Although the morphologies of nanosheets and nanocrystals are different, they show very similar behaviours after ionization. The graph on which the decay of the cation radical signal is plotted shows that an asymptotic value yo greater than $60 \%$ is also reached (Figure 7) while the lifetime of the radical cation is $\tau=134 \mu$ s. This result confirms that most of the cation radicals formed are well stabilized and that the corresponding ejected electrons are trapped by the zeolite framework. The system thus can also evolve partially with slower kinetics towards the CTC as evidenced by experiments performed by conventional spectroscopy.

TRDRUVv nanosponges. The spectra recorded after the excitation of adsorbed t-St in nanosponges are shown in Figure 6. The contribution of the cation radical at $475 \mathrm{~nm}$ is observed but decreases much more rapidly $(\tau=70 \mu \mathrm{s})$, see Figure 7 , than in nanosheet and nanocrystal morphologies. The spectra clearly show that a large part of the cation radical is recombined after $450 \mu$ s unlike what is observed for the other samples. The decay in signal intensity shown in Figure 7 does not evolve to an asymptotic value as previously. This result indicates that recombination takes place quickly and only directly and justifies the fact that the cation radical is not detected for longer periods by steady state spectroscopy.

\section{Discussion}


From these spectral and kinetic data, three distinct behaviours emerge that depend on the host material. However, it is known that the lifetime of photogenerated radical species in the pore volume of zeolites is directly related to the $\mathrm{Si} / \mathrm{Al}$ ratio, the nature of the charge-compensating cation as well as the morphology of the zeolite. ${ }^{22,23}$ In this study, nanocrystals, nanosheets and nanosponges are all MFI zeolite-type with identical charge-compensating cations and with $\mathrm{Si} / \mathrm{Al}$ ratios in the same range $(31,55$ and 33 , respectively). According to the data reported in the literature, the slight variation of the Al content is not significant and is not expected to affect the reaction mechanism. ${ }^{22,23}$ Therefore the change in reactivity must be related to the morphology.

The results obtained after photoexcitation of the t-St incorporated in the ZSM-5 nanocrystals show a behaviour identical to that previously observed with microcrystals of 1-2 $\mu \mathrm{m}$ size and already reported in the literature: after ionization and formation of the cation radical, the stabilized species is CTC. The different steps proposed for these photoinduced electron transfer processes are shown schematically in Figure 8. After t-St adsorption, photoionization occurs near a Lewis acid site and the electron ejected after the radical cation formation $\left(\mathrm{t}-\mathrm{St}^{\bullet+}\right)$ is trapped in the vacant atomic orbital of the $\mathrm{Al}$ atom (stage b). Then, the ejected electron can recombine directly with the radical to give again neutral t-St (stage c) or delocalize by electron hopping to another Lewis acid site (stage d). However, in the case of the nanocrystals, $\mathrm{t}_{-\mathrm{St}}{ }^{\bullet+}$ radicals tend to evolve to charge transfer complex because the redox potential of the cation radical is sufficiently high to capture another electron from a donor site (AlOSi) ${ }^{-}$in the vicinity (stage e). The stabilization of such a CTC is also explained by the electron migration in the framework according to the principle of the charge compartmentalization (stage f). Finally, the disappearance of the CTC corresponds to the recombination of the electron initially ejected and trapped in the zeolite with the positive electronic hole (stage g).

The comparison of the driving forces associated with the different steps depicted in figure 8 might be of interest to describe the electron transfers following the initial photoionization of $t$ stilbene adsorbed in ZSM-5 zeolites (step b). Therefore, this interpretation is based on the kinetic data obtained in the present study corresponding only to stage $g$, the final recombination of CTC and on the data obtained in our previous studies for analogous systems.

In step c (recombination of the cation radical), even if the ejected electron is trapped and delocalized in the framework, it is expected to recombine directly with the radical cation. Such behavior probably happens here with $\mathrm{t}-\mathrm{St}$ but is a minor process. Indeed, this reaction is especially observed when the electron transfer leading to CTC formation is very slow as observed after sorption and ionization of t-St in small pore diameter FER zeolites. ${ }^{22,24}$. In the 
present case, the observation of long lived radical cation as shown by time resolved and steady state DRUVv and the formation of CTC in nanocrystals and nanosheets indicate that direct recombination of $\mathrm{t}_{-\mathrm{St}^{\bullet+}}$ is slower than electron transfer to CTC (step $\mathrm{d}+$ step e). This result is consistent with a large driving force associated with a slow kinetics in the inverted region of Marcus theory. $7,57,58,59$

In step e, CTC formation is the redox reaction between radical cation and zeolite between the $\mathrm{t}-\mathrm{St}^{\bullet+} / \mathrm{t}-\mathrm{St}$ and $\mathrm{Zeo}^{\bullet+} / \mathrm{Zeo}$ pairs (with $\mathrm{t}-\mathrm{St}^{\bullet+} / \mathrm{t}-\mathrm{St}>\mathrm{Zeo}^{\bullet+} / \mathrm{Zeo}$ ) while in step c, the redox pairs involved in the radical recombination are $\mathrm{t}-\mathrm{St}^{\bullet+} / \mathrm{t}-\mathrm{St}$ and $\mathrm{Zeo} / \mathrm{Zeo}^{\bullet-}\left(\right.$ with $\mathrm{t}-\mathrm{St}{ }^{\bullet+} / \mathrm{t}-\mathrm{St}>\mathrm{Zeo} / \mathrm{Zeo}^{\bullet-}$ ). Steps $\mathrm{c}$ and e are in competition but the hole transfer is faster than recombination. On the basis of our results and assuming the reactivity in the inverted region of Marcus theory, it appears that the driving force is smaller for step e than for step c.

In step g corresponding to the final CTC representation, the interpretation can be based on the redox potential diagram again between $\mathrm{Zeo}^{\bullet+} / \mathrm{Zeo}$ and Zeo/Zeo ${ }^{\bullet-}$ pairs (with Zeo ${ }^{\bullet+} /$ Zeo $>$ Zeo/Zeo ${ }^{\bullet-}$ ). Even though, the energy level of $\mathrm{Zeo}^{\bullet+} / \mathrm{Zeo}$ is not known, it is deduced from experiments that the driving force for step $\mathrm{g}$ is necessarily smaller than the reaction of step $\mathrm{c}$, so reaction is faster. Nevertheless, we have to pay attention to this kinetic which depends very strongly on the rate of step $f$.

After adsorption of t-St in the nanosheets, photoexcitation induces the formation of the cation radical which also evolves into CTC but to a lesser extent compared to nanocrystals, the most stable species being clearly the radical cation. Thus, since the formation of the electron/hole pair (CTC) remains low in nanosheets, it seems that this structure does not sufficiently promote the stabilization of the ejected electron. In addition, it should be noted that the stabilization of the ejected electron was found to be directly dependent on the distance between the stabilized electron and the cation radical. ${ }^{60}$ Therefore, it can be deduced that in such a nanosheet environment, the ejected electron cannot be trapped far enough from the cation radical to favour indirect recombination because of the very short length $(2 \mathrm{~nm})$ of the straight channels. This result is consistent with the observations we have already reported after adsorption and photoexcitation of the p-terphenyl molecule in the ZSM-5 nanosheets ${ }^{25}$ where the cation radical was clearly the stabilized species.

To explain the preferential stabilization of the radical cation in the $2 \mathrm{~nm}$ thick nanosheet, we consider the fact that the sheets are never isolated, but are assembled to form a lamellar stacking with a thickness of approximately 20-40 $\mathrm{nm}$. Thus, as discussed above and as shown schematically in Figure 8, the presence of extra-framework $\mathrm{Al}$ associated with the Lewis acid sites can be advanced to explain the formation and stabilization of cation radicals through the 
trapping of the ejected electron into the empty orbital of the $\mathrm{Al}$ atom. The long lifetime of the radical cation is supposed to be due to a process of intergranular sheet-to-sheet migration by electron hopping from one Lewis acid site to another, even if a priori no covalent chemical bond exists between the nanosheets within these agglomerates. In the same way, the CTC formation in small quantities is assumed to occur in a $(\mathrm{SiOAl})^{-}$site in the proximity either in the channel of the sheet where the ionization took place or in a neighbour sheet. The relatively low $\mathrm{Al}_{\text {framework }}$ content $\left(\mathrm{Si} / \mathrm{Al}_{\mathrm{f}}=55\right)$ does not seem to favour this reaction mechanism. Anyway, the stabilization of CTC might also be explained by the compartmentalization principle and the electron migration across several sheets. A second hypothesis could involve the participation of sinusoidal channels in electronic transfer processes. Indeed, if the $2 \mathrm{~nm}$ length of the straight channels of the nanosheets seems too short to ensure the stabilization of the electron/hole pairs, the length of the sinusoidal channels can reach several tens or even hundreds of nanometers, a distance largely sufficient to relocate and thus stabilize the ejected electron.

In the case of nanosponges, the reactivity is clearly different from that observed in both nanocrystals and nanosheets. No stable species could be observed for times longer than some tens of $\mu \mathrm{s}$, despite the fact that the presence of the transient cation radical and the Raman spectra confirmed the adsorption of the t-St molecule within the nanosponges. The absence of a cation radical signal over longer periods of time and, above all, the non-observation of CTC, as was logically expected, must be a consequence of the particular morphology of the nanosponges. As mentioned above, nanosponges consist of nanocrystals interconnected together and separated by mesopores whose size is close to $5.8 \mathrm{~nm} .{ }^{31}$ Even if the length of the straight channels is the same in nanosponges as in nanosheets, the different morphology of nanosponges means that no stacking effect can be considered with this material to explain the charge stabilization. Consequently, if the molecule adsorbs to the straight channel as predicted by molecular modelling for a complete ZSM-5 framework, ${ }^{51}$ only one molecule about $1 \mathrm{~nm}$ long could be incorporated into this channel. This molecule would be then very close to the pore opening of the zeolite and the stabilization of the photoinduced cation radical could not be effective since the ejected electron does not have the possibility to migrate over long distances by compartmentalization along the straight channels or by migration from one sheet to the other. Then, as envisaged for nanosheets, the role of sinusoidal channels could be considered. However, as experiments show that there is no stabilization of CSS in nanosponges, the transfer of electrons through the sinusoidal pores of the nanosponges and therefore also of the nanosheets is unlikely. 
In this context, the confinement effect must be considered as very important in stabilizing radical species within the porous network. ${ }^{22,23,24}$ In particular, it has been shown that after ionization of t-St or other probe molecules adsorbed in the pores of channel zeolites, the very long lifetime of cation radicals in FER-type zeolite gradually decreased as pore diameter size increased from ZSM-5 to MOR to *BEA. On the other hand, the adsorption of probe molecules in zeolites formed by a network of cages and cavities with larger openings such as FAU (1.4$1.5 \mathrm{~nm}$ ) does not stabilize long-lived photoinduced radicals. ${ }^{61}$

In our sample, the adsorption of t-St in the different levels of porosity of nanosponges must be considered. Indeed, as indicated in table 1 , the microporosity is higher within nanosponges $(0.3$ $\left.\mathrm{cm}^{3} \cdot \mathrm{g}^{-1}\right)$ than in nanosheets $\left(0.18 \mathrm{~cm}^{3} \cdot \mathrm{g}^{-1}\right)$ because they contain some secondary micropores induced by the presence of $\mathrm{C}_{18-6-6} \mathrm{C}_{18}$ in the synthesis gel in addition to the micropores of the MFI-type framework. The diameter of these additional secondary micropores is around 1-1.5 $\mathrm{nm}$. Moreover, nanosponges are also constituted by mesopores with an average pore diameter of approximately $5.8 \mathrm{~nm} .{ }^{31}$ Thus, as explained above, the stabilization of charge separated states can only occur when the confinement effect is high enough to slow down electron transfer kinetics. Based on the data obtained for nano/microcrystals and taking into account that no spectral signature is detected after excitation by steady state spectroscopies, it is reasonable to propose that $\mathrm{t}-\mathrm{St}$ is not adsorbed within the micropores of the MFI-type framework of nanosponges but rather within the secondary microporosity or within mesopores. The lifetime of t-St radical cation obtained after photoexcitation of the $\mathrm{t}-\mathrm{St}$ adsorbed in the nanosponges is of the same order of magnitude as that measured in the FAU zeolite where the diameter of the supercage is similar to that of the secondary micropores. In such an environment, confinement is not sufficient to stabilize the separate charge states and recombination takes place directly without subsequent electron transfer. In the same way, the adsorption in the secondary micropores would lead to ultrafast phenomena compared to those observed in the microporous MFI-type framework where the guest molecule does not fit with the cavities. Unfortunately, we cannot distinguish the reactivity in the second level of microporosity from that in the mesopores and then differentiate the electron transfers in these two larger pore diameter environments.

It should be noted that photoisomerization of trans-stilbene to cis-stilbene has never been observed during excitation of adsorbed t-St in nanocrystals, nanosheets and nanosponges. Indeed, isomerization of t-St incorporated into the channels of ZSM-5 nanocrystals and nanosheets was not expected due to steric hindrance because cis-stilbene does not fit in the channels of the MFI-type framework ZSM-5. ${ }^{53}$ In addition, although photoisomerization of $\mathrm{t}$ St to form the radical cation cis-St could be considered for nanosponges if t-St is initially 
incorporated into the second microporosity level (with large pore diameter) or mesoporosity of the nanosponges, its spectral signature has never been observed.

Thus, even if the Lewis acid site is in the immediate vicinity of the ionization site to trap the ejected electron, delocalization cannot take place in the absence of a lamellar structure as in nanosheets and therefore stabilization of the CSS cannot take place. Finally, it is interesting to note that the relatively large amount of Lewis acid sites (30\%) in the nanosponges and in the nanosheets $(20 \%)$ should lead to a similar rate of ionization that is not observed. This result shows that the effect of morphology is clearly the key factor in explaining the reactivity within these porous nanomaterials.

\section{Conclusion}

The objective of this study was to highlight a possible dependence of photoinduced charge separated states in ZSM-5 zeolites on the morphology of ZSM-5-type material in terms of stabilized species and lifetimes. In nanocrystals, the results obtained show that cation radicals recombine mostly indirectly by generating charge transfer complexes (CTC). Time-resolved spectroscopy have shown that the hole transfer that led to the formation of the CTC takes place over relatively long periods of time much longer than $1 \mathrm{~ms}$. In the $2 \mathrm{~nm}$ thick nanosheets, the cation radical and CTC were detected but the cation radical appears more stable. The short length of the straight channels in which the molecules adsorb is invoked to explain the greater stability of cation radicals since the delocalization of electrons by compartmentalization in this channel cannot take place. Nevertheless, CTC observation suggests that this relocation also exists and is interpreted by the stacking of sheets and the relocation of the ejected electron by interparticle hopping. In nanosponges, steady state absorption spectroscopy does not detect any radical species. These species are only observed by transient UV-vis spectroscopy for a lifetime of a few tens of $\mu$ s. In this environment, the cation radical does not evolve towards the CTC and recombines directly. Then the location of adsorbed molecules in the secondary microporosity and/or in the mesopores where confinement is too weak to stabilize separate charge states is proposed to explain the low stability in the nanosponges. The delocalization of electrons in a sheet via sinusoidal channels measuring up to several hundred of nanometers could also be considered but this hypothesis is not compatible with the results observed in nanosponges. Indeed, nanosponges being composed of organized nanosheets present the same type of sinusoidal channels and show no ability to stabilize these radical species. 


\section{Conflicts of interest:}

There are no conflicts of interest to declare

\section{Acknowledgments:}

Financial support from the Chevreul institute (FR 2638), the Ministère de l'Enseignement Supérieur et de la Recherche, Région Hauts de France and FEDER is acknowledged. L. Duplouy would like to thank the Région Haut de France for $\mathrm{PhD}$ grant. The authors acknowledge the Characterisation plateforme of the Chevreul Institute for the FT-Raman facilities and support.

\section{References}

1. H. Liu, D. Cheng, F. Chen and X. Zhan, Porous lantern-like MFI zeolites composed of 2D nanosheets for highly efficient visible light-driven photocatalysis, Catal. Sci. Technol., 2020, 10, 351-359.

2. M. Liu, Y. Ren, J. Wu, Y. Wang, J. Chen, X. Lei and X. Zhu, Effect of cations on the structure, physico-chemical properties and photocatalytic behaviors of silver-doped zeolite Y, Microporous and Mesoporous Materials, 2020, 293, 109800.

3. C. Aprile, L. Maretti, M. Alvaro, J. C. Scaiano and H. Garcia, Long-lived (minutes) photoinduced charge separation in a structured periodic mesoporous titania containing $2,4,6$ triphenylpyrylium as guest, Dalton Trans., 2008, 5465-5470.

4. K. T. Ranjit and L. Kevan, Photoinduced Charge Separation of N,N,N'N`-

Tetramethylbenzidine in Chromium Ion-Exchanged Zeolite $\mathrm{X}$ at Room Temperature, J. Phys. Chem. B, 2002, 106, 9306-9312

5. H. Qi, H. Liu, L. Zhang and J. Wu, Photodegradation of Methyl Orange Over CdS-TiO2/Lzeolite Composite Photocatalyst, J Inorg Organomet Polym, 2019, 29, 564-571.

6. B. Pattengale and J. Huang, Photoinduced interfacial charge separation dynamics in zeolitic imidazolate framework, Phys. Chem. Chem. Phys., 2018, 20, 14884-14888.

7. S. Fukuzumi, A. Itoh, K. Ohkubo and T. Suenobu, Size-selective incorporation of donoracceptor linked dyad cations into zeolite $\mathrm{Y}$ and long-lived charge separation, $R S C A d v$., 2015, 5, 45582-45585.

8. R. T. Koodali, Photoinduced charge separation in microporous and mesoporous materials, Can. J. Chem., 2011, 89, 257-265.

9. P. K. Dutta and M. Severance, Photoelectron Transfer in Zeolite Cages and Its Relevance to Solar Energy Conversion, J. Phys. Chem. Lett., 2011, 2, 467-476.

10. H. Zhang, C. S. Rajesh and P. K. Dutta, Ruthenium Polypyridyl Complexes Containing a Conjugated Ligand LDQ (LDQ = 1-[4-(4'-methyl)-2,2'-bipyridyl]-2-[4-(4'-N,N'tetramethylene-2,2'-bipyridinum)]ethene): Synthesis, Characterization, and Photoinduced Electron Transfer at Solution-Zeolite Interfaces, J. Phys. Chem. C, 2009, 113, 4623-4633. 11. Y. Kim, A. Das, H. Zhang and P. K. Dutta, Zeolite Membrane-Based Artificial Photosynthetic Assembly for Long-Lived Charge Separation, J. Phys. Chem. B, 2005, 109, 6929-6932.

12. M. Álvaro, J. F. Cabeza, D. Fabuel, A. Corma and H. García, Electrochemiluminescent Cells Based on Zeolite-Encapsulated Host-Guest Systems: Encapsulated Ruthenium Trisbipyridyl, Chemistry - A European Journal, 2007, 13, 3733-3738. 
13. P. Atienzar, S. Valencia, A. Corma and H. García, Titanium-Containing Zeolites and Microporous Molecular Sieves as Photovoltaic Solar Cells, ChemPhysChem, 2007, 8, 11151119.

14. G. Calzaferri, H. Li and D. Brühwiler, Dye-Modified Nanochannel Materials for

Photoelectronic and Optical Devices, Chemistry - A European Journal, 2008, 14, 7442-7449.

15. A. Devaux, G. Calzaferri, P. Belser, P. Cao, D. Brühwiler and A. Kunzmann, Efficient and Robust Host-Guest Antenna Composite for Light Harvesting, Chem. Mater., 2014, 26, $6878-6885$.

16. H. García and H. D. Roth, Generation and Reactions of Organic Radical Cations in Zeolites, Chem. Rev., 2002, 102, 3947-4008.

17. J. R. Kincaid, The Development of Zeolite-Entrapped Organized Molecular Assemblies, Chemistry - A European Journal, 2000, 6, 4055-4061.

18. Y. S. Park, E. J. Lee, Y. S. Chun, Y. D. Yoon and K. B. Yoon, Long-Lived Charge-

Separation by Retarding Reverse Flow of Charge-Balancing Cation and Zeolite-Encapsulated Ru(bpy)32+ as Photosensitized Electron Pump from Zeolite Framework to Externally Placed Viologen, J. Am. Chem. Soc., 2002, 124, 7123-7135.

19. G. Zhang and J. K. Thomas, Effect of Charge Stabilization on Electron Transfer Reactions in Zeolites, J. Phys. Chem. B, 2003, 107, 7254-7260.

20. A. Moissette, M. Hureau, P. Col and H. Vezin, Electron Transfers in Donor-Acceptor Supramolecular Systems: Highlighting the Dual Donor and Acceptor Role of ZSM-5 Zeolite, J. Phys. Chem. C, 2016, 120, 17372-17385.

21. A. Moissette, M. Hureau, P. Col and H. Vezin, Electron Transfers in Donor-Acceptor Supramolecular Systems: Highlighting the Dual Donor and Acceptor Role of ZSM-5 Zeolite, J. Phys. Chem. C, 2016, 120, 17372-17385.

22. M. Hureau, A. Moissette, A. Legrand, F. Luchez, M. Sliwa and C. Bremard, Chemical Control of Photoinduced Charges under Confinement in Zeolites, J. Phys. Chem. C, 2012, 116, 9092-9105.

23. A. Moissette, M. Hureau, H. Vezin and R. F. Lobo, in Chemistry of Silica and ZeoliteBased Materials, eds. A. Douhal and M. Anpo, Elsevier, 2019, vol. 2, pp. 249-271.

24. M. Hureau, A. Moissette, H. Vezin, C. Brémard and M. Orio, Influence of Confinement Effect on Electron Transfers Induced by t-Stilbene Sorption in Medium Pore Acidic Zeolites, J. Phys. Chem. C, 2012, 116, 1812-1825.

25. M. Hureau, A. Moissette, L. Tzanis and T. J. Daou, Effects of the zeolite particle size on the charge separated states, Microporous and Mesoporous Materials, 2017, 254, 121-127. 26. M. Gil, J. A. Organero, E. Peris, H. García and A. Douhal, Confinement effect of nanocages and nanotubes of mesoporous materials on the keto forms photodynamics of Sudan I, Chemical Physics Letters, 2009, 474, 325-330.

27. X. H. Vu, T. T. Truong and U. Armbruster, Enhanced cracking of bulky hydrocarbons over hierarchical ZSM-5 materials: a comparative study, J Porous Mater, 2019, 26, 175-184. 28. Q. Zhang, A. Mayoral, O. Terasaki, Q. Zhang, B. Ma, C. Zhao, G. Yang and J. Yu, Amino Acid-Assisted Construction of Single-Crystalline Hierarchical Nanozeolites via OrientedAggregation and Intraparticle Ripening, J. Am. Chem. Soc., 2019, 141, 3772-3776.

29. S. Shetsiri, A. Thivasasith, K. Saenluang, W. Wannapakdee, S. Salakhum, P. Wetchasat, S. Nokbin, J. Limtrakul and C. Wattanakit, Sustainable production of ethylene from bioethanol over hierarchical ZSM-5 nanosheets, Sustainable Energy Fuels, 2018, 3, 115-126. 30. L. Meng, X. Zhu, W. Wannapakdee, R. Pestman, M. G. Goesten, L. Gao, A. J. F. van Hoof and E. J. M. Hensen, A dual-templating synthesis strategy to hierarchical ZSM-5 zeolites as efficient catalysts for the methanol-to-hydrocarbons reaction, Journal of Catalysis, 2018, 361, 135-142. 
31. I. Kabalan, B. Lebeau, H. Nouali, J. Toufaily, T. Hamieh, B. Koubaissy, J.-P. Bellat and T. J. Daou, New Generation of Zeolite Materials for Environmental Applications., J. Phys. Chem. C, 2016, 120, 2688-2697.

32. A. Astafan, M. A. Benghalem, Y. Pouilloux, J. Patarin, N. Bats, C. Bouchy, T. J. Daou and L. Pinard, Particular properties of the coke formed on nano-sponge *BEA zeolite during ethanol-to-hydrocarbons transformation, Journal of Catalysis, 2016, 336, 1-10.

33. A. Astafan, Y. Pouilloux, J. Patarin, N. Bats, C. Bouchy, T. J. Daou and L. Pinard, Impact of extreme downsizing of *BEA-type zeolite crystals on n-hexadecane hydroisomerization, New J. Chem., 2016, 40, 4335-4343.

34. T. Cremoux, I. Batonneau-Gener, A. Moissette, J.-L. Paillaud, M. Hureau, E. Ligner, C. Morais, S. Laforge, C. Marichal and H. Nouali, Influence of hierarchization on electron transfers in structured MFI-type zeolites, Phys. Chem. Chem. Phys., 2018, 20, 26903-26917. 35. R. Feng, X. Yan, X. Hu, Y. Zhang, J. Wu and Z. Yan, Phosphorus-modified b-axis oriented hierarchical ZSM-5 zeolites for enhancing catalytic performance in a methanol to propylene reaction, Applied Catalysis A: General, 2020, 594, 117464.

36. M. Arroyo, L. Briones, J. M. Escola and D. P. Serrano, Conversion of Stearic Acid into Bio-Gasoline over Pd/ZSM-5 Catalysts with Enhanced Accessibility, Applied Sciences, 2019, 9, 2386.

37. S. Zhao, W. D. Wang, L. Wang, W. Schwieger, W. Wang and J. Huang, Tuning Hierarchical ZSM-5 Zeolite for Both Gas- and Liquid-Phase Biorefining, ACS Catal., 2020, 10, 1185-1194.

38. L. Xu, F. Wang, Z. Feng, Z. Liu and J. Guan, Hierarchical ZSM-5 Zeolite with Enhanced Catalytic Activity for Alkylation of Phenol with Tert-Butanol, Catalysts, 2019, 9, 202.

39. M. Choi, K. Na, J. Kim, Y. Sakamoto, O. Terasaki and R. Ryoo, Stable single-unit-cell nanosheets of zeolite MFI as active and long-lived catalysts, Nature, 2009, 461, 246-249. 40. K. Na, C. Jo, J. Kim, K. Cho, J. Jung, Y. Seo, R. J. Messinger, B. F. Chmelka and R. Ryoo, Directing Zeolite Structures into Hierarchically Nanoporous Architectures, Science, 2011, 333, 328-332.

41. J. Dhainaut, T. J. Daou, Y. Bidal, N. Bats, B. Harbuzaru, G. Lapisardi, H. Chaumeil, A. Defoin, L. Rouleau and J. Patarin, One-pot structural conversion of magadiite into MFI zeolite nanosheets using mononitrogen surfactants as structure and shape-directing agents, CrystEngComm, 2013, 15, 3009-3015.

42. X. Jia, W. Khan, Z. Wu, J. Choi and A. C. K. Yip, Modern synthesis strategies for hierarchical zeolites: Bottom-up versus top-down strategies, Advanced Powder Technology, 2019, 30, 467-484.

43. I. Kabalan, G. Rioland, H. Nouali, B. Lebeau, S. Rigolet, M.-B. Fadlallah, J. Toufaily, T. Hamiyeh and T. J. Daou, Synthesis of purely silica MFI-type nanosheets for molecular decontamination, RSC Adv., 2014, 4, 37353-37358.

44. D. Massiot, F. Fayon, M. Capron, I. King, S. L. Calvé, B. Alonso, J.-O. Durand, B. Bujoli, Z. Gan and G. Hoatson, Modelling one- and two-dimensional solid-state NMR spectra, Magnetic Resonance in Chemistry, 2002, 40, 70-76.

45. M. Guisnet, P. Ayrault and J. Datka, Acid properties of dealuminated mordenites studied by IR spectroscopy. 2. Concentration, acid strength and heterogeneity of $\mathrm{OH}$ groups, Polish Journal of Chemistry, 1997, 71, 1455-1461.

46. W. J. Albery, P. N. Bartlett, C. P. Wilde and J. R. Darwent, A general model for dispersed kinetics in heterogeneous systems, Journal of the American Chemical Society, 1985, 107, 1854-1858.

47. M. Nič, J. Jirát, B. Košata, A. Jenkins and A. McNaught, IUPAC compendium of chemical terminology. IUPAC Res. Triagle Park NC (2009). 
48. S. Brunauer, P. H. Emmett and E. Teller, Adsorption of Gases in Multimolecular Layers. $J$. Am. Chem. Soc., 1938, 60, 309-319.

49. L. El Hanache, L. Sundermann, B. Lebeau, J. Toufaily, T. Hamieh and T. J. Daou, Surfactant-modified MFI-type nanozeolites: Super-adsorbents for nitrate removal from contaminated water, Microporous and Mesoporous Materials, 2019, 283, 1-13.

50. Olsson, R. W. \& Rollmann, L. D. Crystal chemistry of dealuminized mordenites. Inorg.

Chem. 16, 651-654 (1977).

51. M. Hureau, A. Moissette, K. S. Smirnov and H. Jobic, Combined Spectroscopic and Modeling Study of trans-Stilbene Molecule in Cation-Exchanged ZSM-5 Zeolites, J. Phys. Chem. C, 2012, 116, 15510-15518.

52. I. K. Lednev, N. Mathivanan, L. J. Johnston, Photochemistry of Stilbene Adsorbed on Silica Gel and NaX Zeolite. A Diffuse Reflectance Laser Flash Photolysis Study, J. Phys. Chem., 1994, 98, 11444-11451.

53. P. H. Lakshminarasimhan, R. B. Sunoj, S. Karthikeyan, J. Chandrasekhar, L. J. Johnston, and V. Ramamurthy, Direct and sensitized (energy and electron transfer) geometric isomerization of stilbene within zeolites: a comparison between solution and zeolite as reaction media, Journal of Photochemistry and Photobiology, A: Chemistry, 2002, 153, 41-53.

54. S. Samori, M. Hara, S. Tojo, M. Fujitsuka, T. Majima, Journal of Photochemistry and Photobiology A: Chemistry, 2006, 179, 115-124

55. A. E. Keirstead, N. P. Schepp and F. L. Cozens, Influence of the Alkali Metal Cation on the Distance of Electron Migration in Zeolite Y: A Nanosecond Laser Photolysis Study, J. Phys. Chem. C, 2007, 111, 14247-14252.

56. M. A. O’Neill, F. L. Cozens and N. P. Schepp, Photogeneration and Migration of Electrons and Holes in Zeolite NaY, J. Phys. Chem. B, 2001, 105, 12746-12758.

57. N. A. Garcia \& T. Kowalczyk, Extension of Intramolecular Charge-Transfer State Lifetime by Encapsulation in Porous Frameworks. J. Phys. Chem. C, 2017, 121, 20673-20679.

58. R.A. Marcus, Electron transfer reactions in chemistry theory and experiment, $J$. Electroanal. Chem., 1997, 438, 251-259.

59. R.A. Marcus \& N. Sutin, Electron transfers in chemistry and biology, BBA Bioenergetics 1985, 811, 265-322.

60. M. Hureau, A. Moissette, J. Gaillard and C. Brémard, Photoinduced electron transfers in zeolites: impact of the aluminum content on the activation energies, Photochem. Photobiol. Sci., 2012, 11, 1515-1519.

61. I. Gener, G. Buntinx, A. Moissette and C. Brémard, Photochemistry of Biphenyl Occluded within X Faujasite Type Zeolites, J. Phys. Chem. B, 2002, 106, 10322-10329. 
Table 1: Textural parameters and amount of acid sites in the nanomaterials

\begin{tabular}{l|ccc|cccc}
\hline \multicolumn{1}{l|}{} & \multicolumn{1}{c}{ Porosity } \\
\hline Samples & $\mathrm{Si} / \mathrm{Al}_{\text {global }}$ & $\mathrm{Si} / \mathrm{Al}$ framework & $\begin{array}{c}\text { EFAL } \\
(\%)\end{array}$ & $\mathrm{V}_{\text {total }}\left(\mathrm{cm}^{3} \cdot \mathrm{g}^{-1}\right)$ & $\mathrm{V}_{\text {micro }}\left(\mathrm{cm}^{3} \cdot \mathrm{g}^{-1}\right)$ & $\mathrm{V}_{\text {meso }}\left(\mathrm{cm}^{3} \cdot \mathrm{g}^{-1}\right)$ & $\mathrm{S}_{\mathrm{BET}}\left(\mathrm{m}^{2} \cdot \mathrm{g}^{-1}\right)$ \\
\hline nanocrystals & 29.7 & 31 & 1 & 0.33 & 0.16 & 0.169 & 382 \\
nanosheets & 44 & 55 & 20 & 0.54 & 0.18 & 0.36 & 492 \\
nanosponges & 23 & 33 & 30 & 1.28 & 0.3 & 0.78 \\
\hline
\end{tabular}

\begin{tabular}{l|c}
\hline & Acidity \\
\hline Samples & Lewis $\left(150^{\circ} \mathrm{C}\right)\left(\mu \mathrm{mol} \mathrm{g}{ }^{-1}\right)$ \\
\hline nanocrystals & 50 \\
nanosheets & 80 \\
nanosponges & 103 \\
\hline
\end{tabular}

${ }^{\mathrm{a}} \mathrm{Si} / \mathrm{Al}$ molar ratio of the sample determined by XRF

${ }^{\mathrm{b}} \mathrm{Si} / \mathrm{Al}$ molar ratio of the zeolite framework determined from XRF and ${ }^{27} \mathrm{Al}$ MAS NMR

${ }^{\mathrm{d}}$ Concentration of pyridine adsorbed on Lewis acid sites following the thermo-desorption at $150{ }^{\circ} \mathrm{C}$.

Table 2: Lifetimes and kinetic constants for the radical cation (RC) and for the charge transfer complex (CTC) obtained using diffuse reflectance UV-vis (DRUVv) and time resolved diffuse reflectance UV-vis (TRDRUVv) spectroscopies.

\begin{tabular}{l|cccc|ccc}
\cline { 2 - 8 } & \multicolumn{5}{c|}{ DRUVv } & \multicolumn{2}{c}{ TRDRUVv } \\
\cline { 2 - 8 } & $\mathrm{RC}$ & $\mathrm{CTC}$ & $\mathrm{RC}$ & $\mathrm{CTC}$ & $\mathrm{RC}$ & $\mathrm{CTC}$ & $\mathrm{RC}$ \\
\hline Samples & $\mathrm{t}(\mathrm{min})$ & $\mathrm{t}(\mathrm{min})$ & $\mathrm{k}\left(\mathrm{min}^{-1}\right)$ & $\mathrm{k}\left(\mathrm{min}^{-1}\right)$ & $\mathrm{t}(\mathrm{ms})$ & $\mathrm{t}(\mathrm{ms})$ & $\mathrm{k}\left(\mathrm{ms}^{-1}\right)$ \\
\hline nanocrystals & 24 & 96 & 0.0412 & 0.0050 & 600 & - & 0.00167 \\
nanosheets & 200 & 70 & 0.0105 & 0.0142 & 134 & - & 0.00746 \\
nanosponges & - & - & - & - & 70 & - & 0.01429 \\
\hline
\end{tabular}



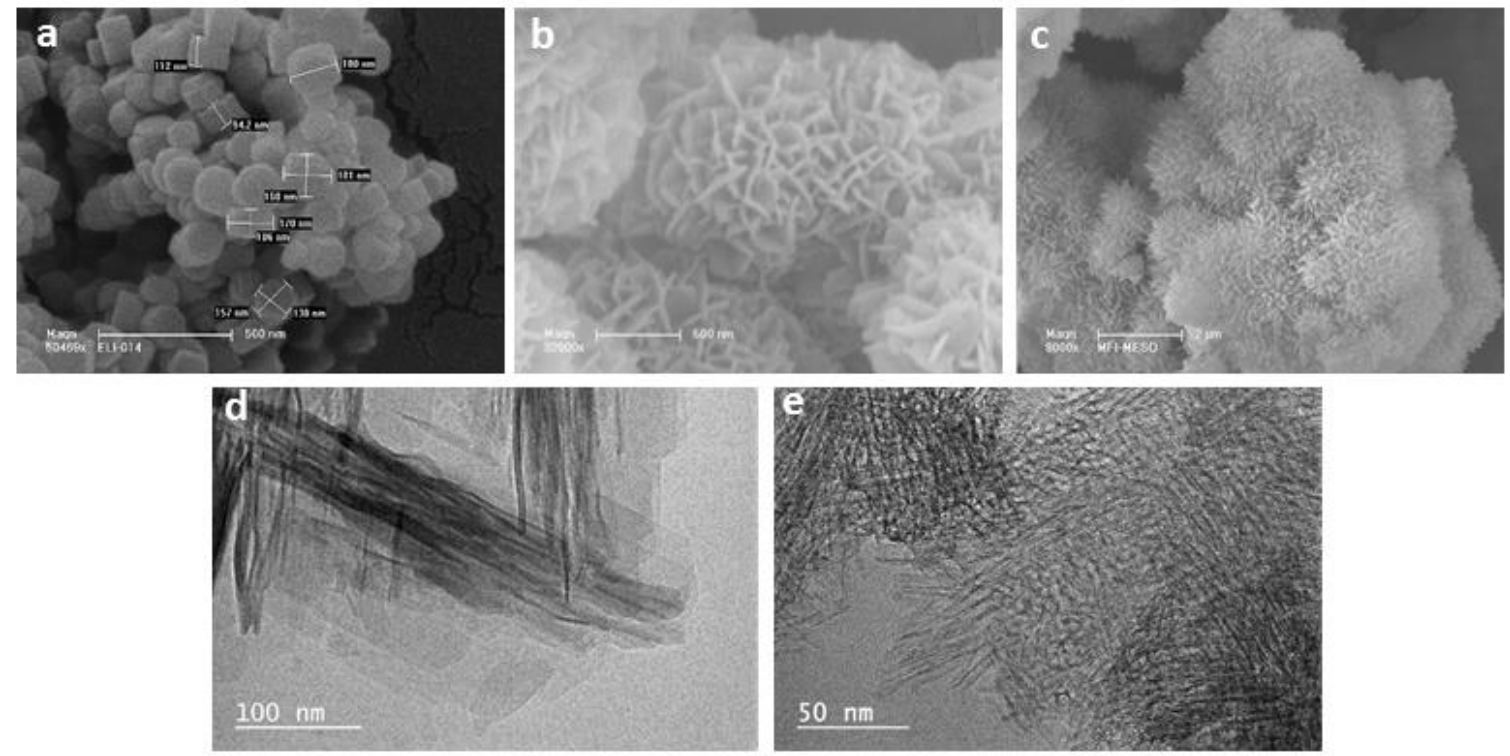

Figure 1 : SEM images obtained for nanocrystals (a), nanosheets (b) and nanosponges (c) and TEM images of nanosheets (d) and nanosponges (e). 


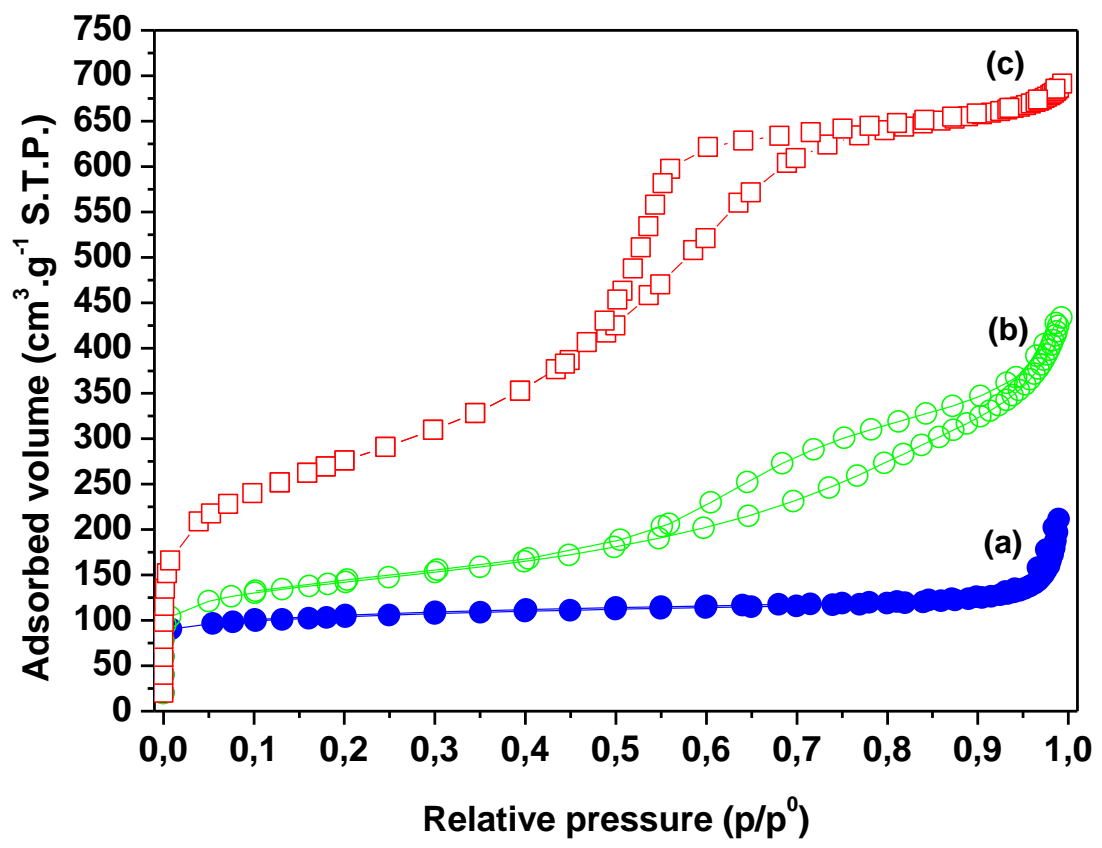

Figure $2: \mathrm{N}_{2}$ adsorption/desorption isotherms obtained at $-196{ }^{\circ} \mathrm{C}$ for calcined nanocrystals (a), nanosheets (b) and nanosponges (c). 


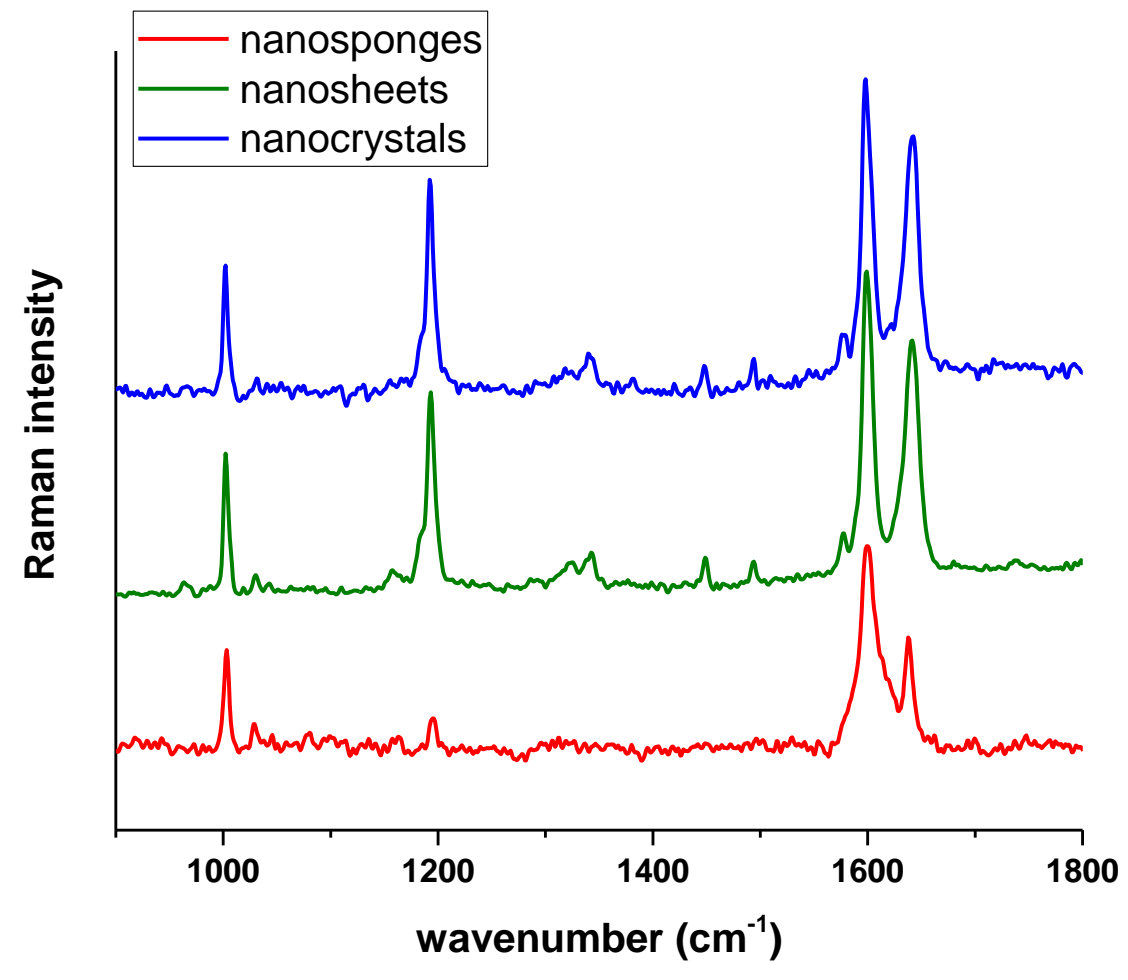

Figure 3 : FT-Raman spectra $\left(\lambda_{\mathrm{ex}}=1064 \mathrm{~nm}\right)$ obtained 6 months after mixing t-St and nanocrystals, nanosheets and nanosponges, respectively 

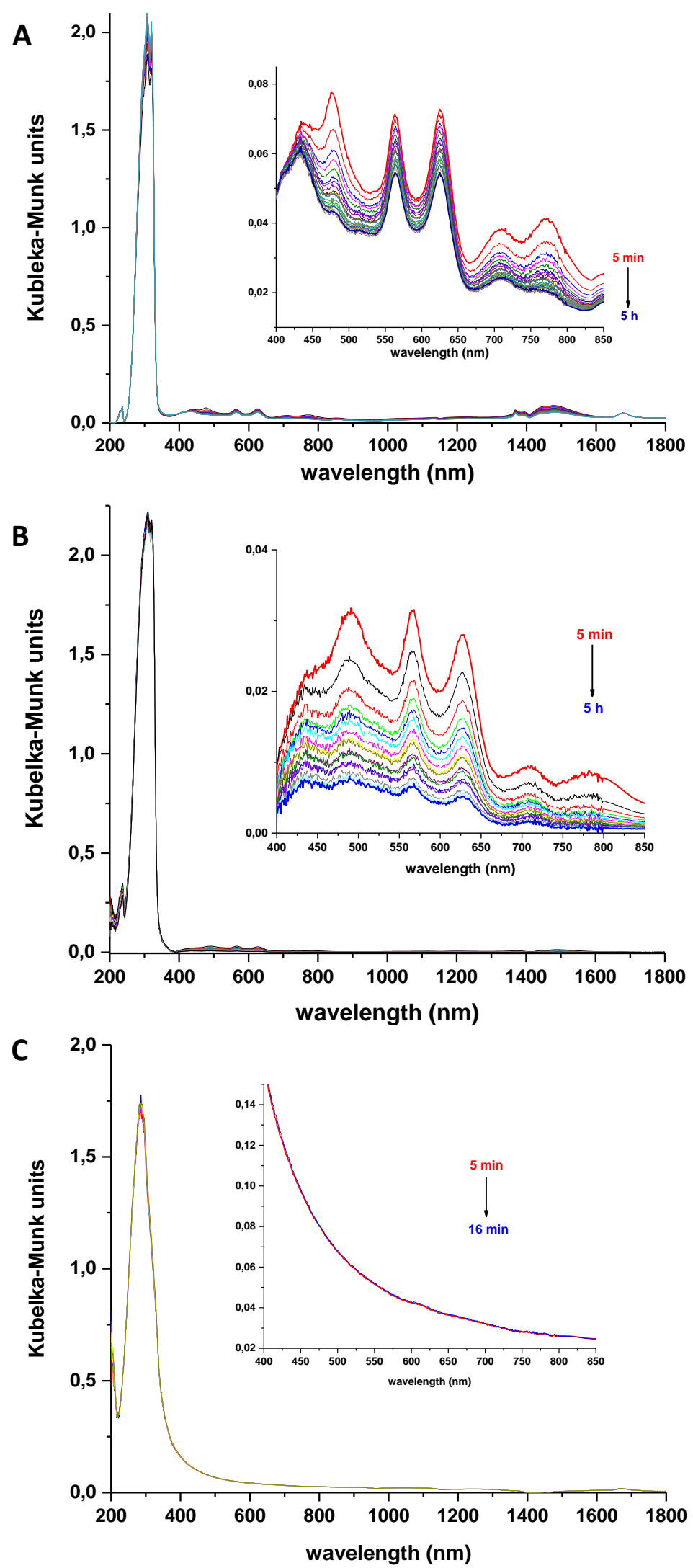

Figure 4: Diffuse reflectance UV-vis spectra obtained after irradiation of t-St incorporated in ZSM-5 nanocrystals (A), nanosheets (B) and nanosponges (C). 

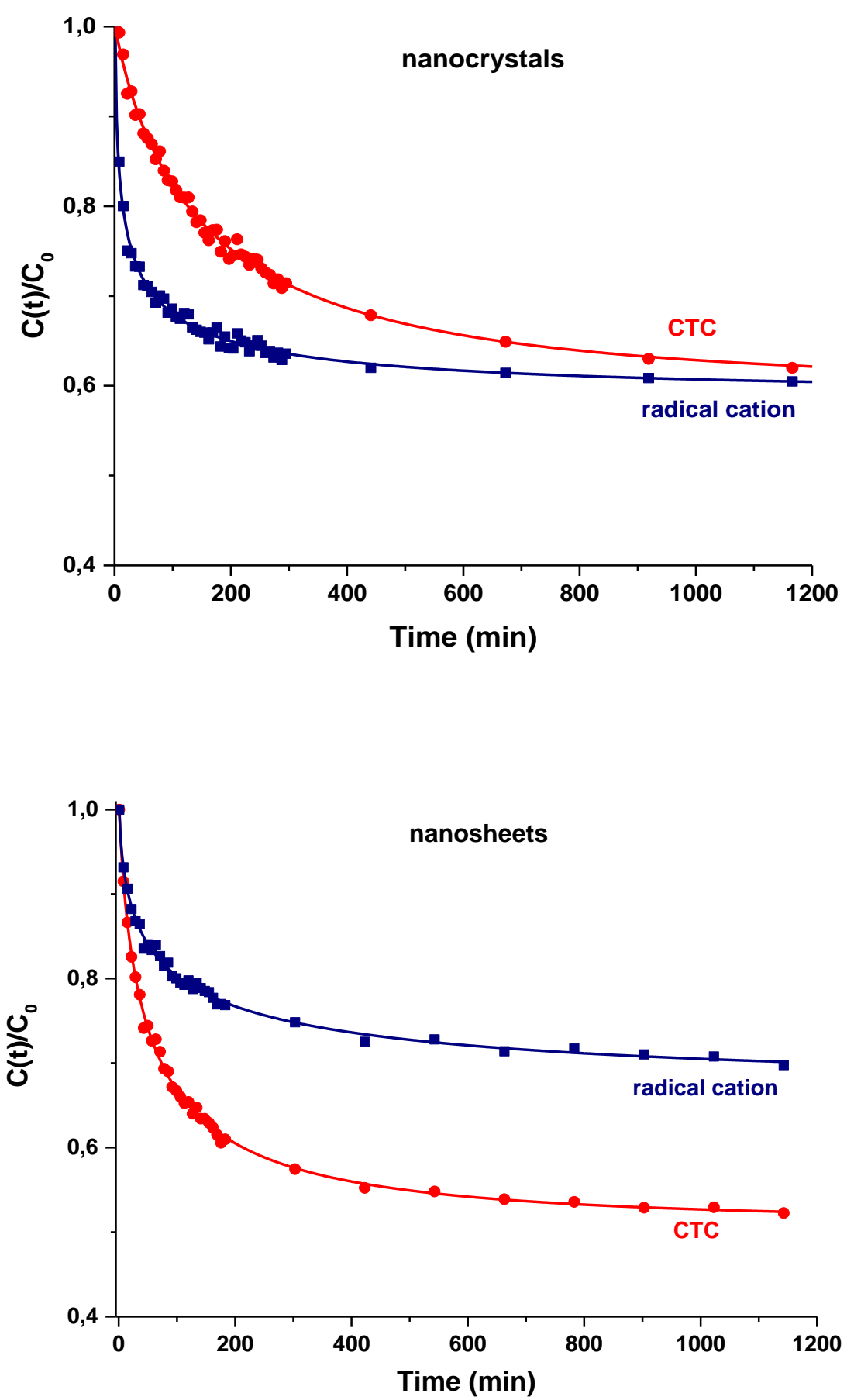

Figure 5: Diffuse reflectance UV-vis $\mathrm{C}(\mathrm{t}) / \mathrm{C} 0$ decays for radical cation and $\mathrm{CTC}$ measured at $475 \mathrm{~nm}$ and $620 \mathrm{~nm}$ respectively, obtained after irradiation of t-St incorporated in ZSM-5 nanocrystals and nanosheets 

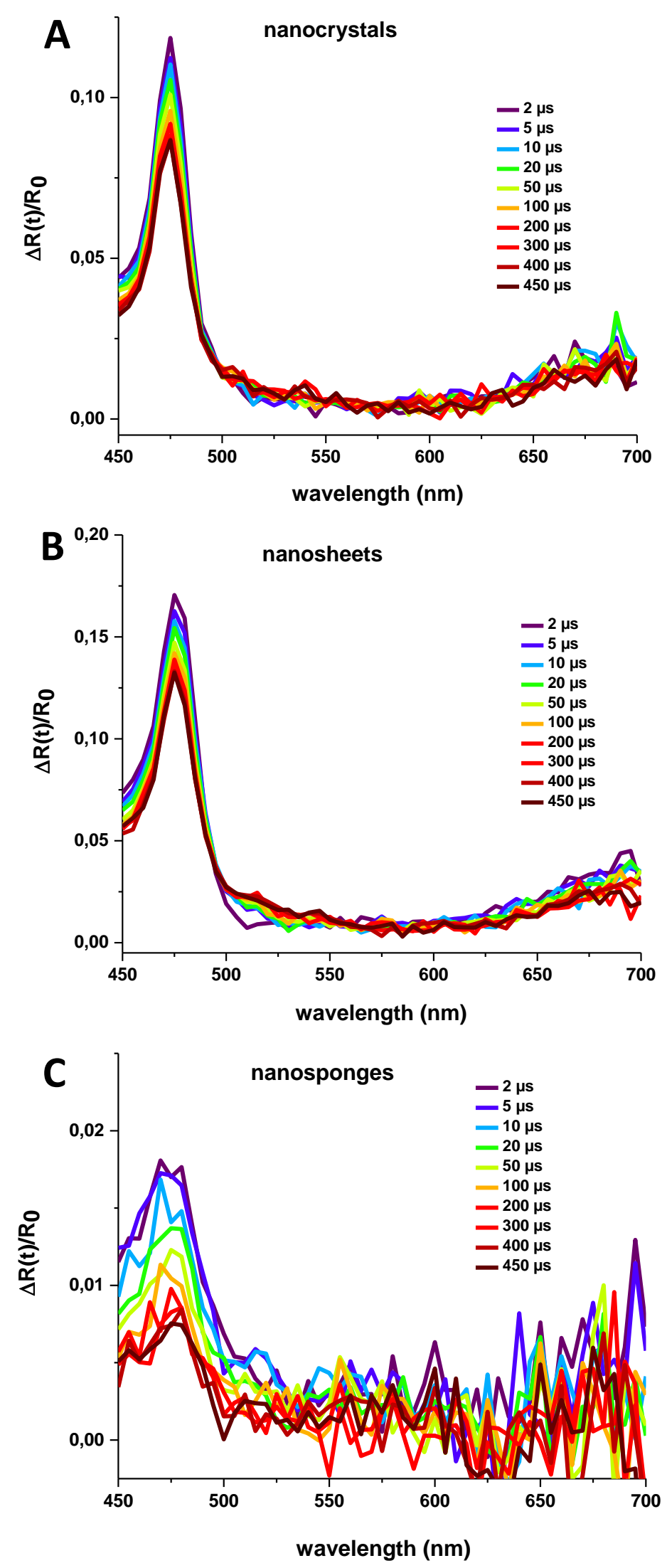

Figure 6: Time resolved diffuse reflectance UV-vis spectra obtained after irradiation of t-St incorporated in ZSM-5 nanocrystals (A), nanosheets (B) and nanosponges (C). 


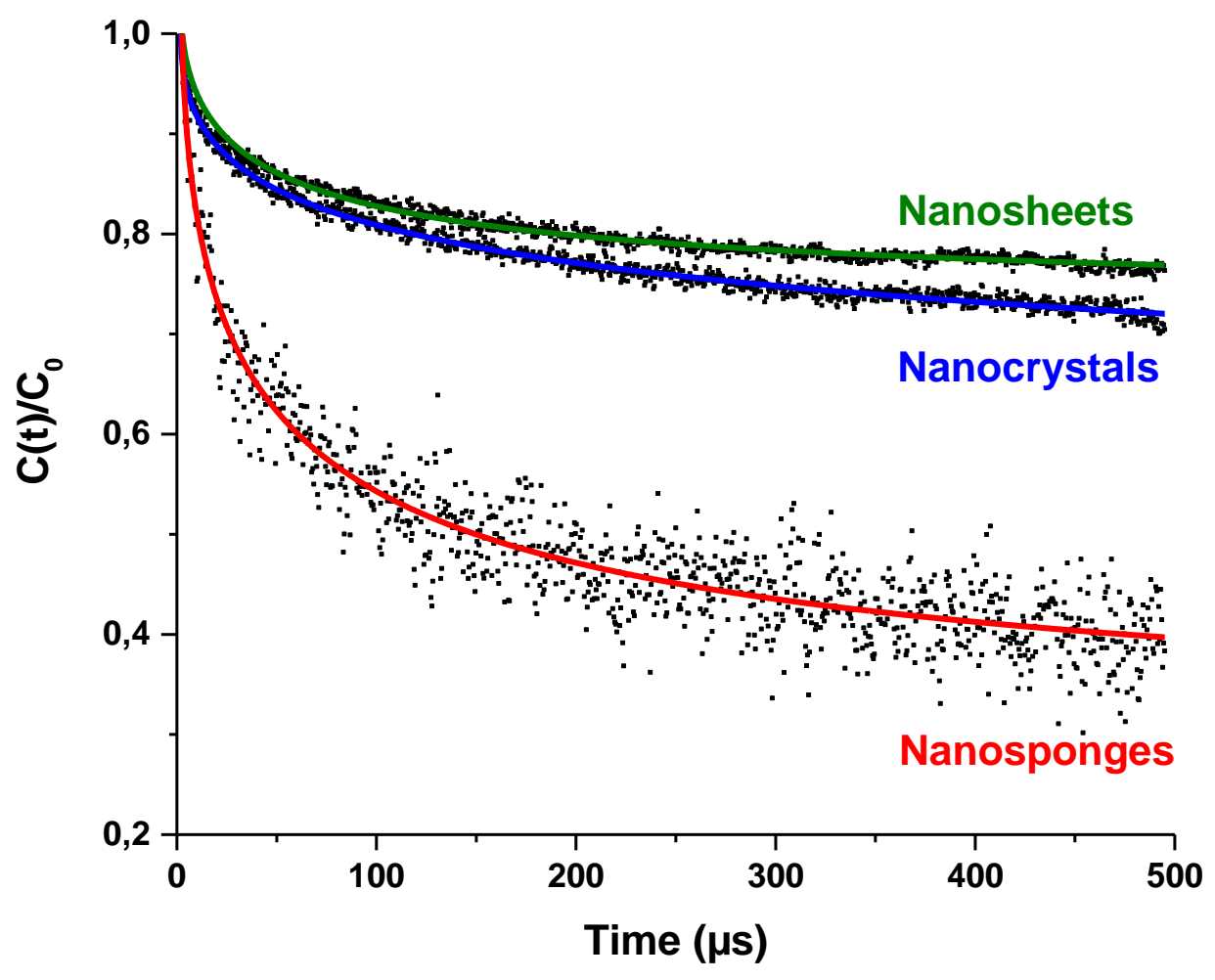

Figure 7: Decay profiles of Radical Cation concentration measured at $475 \mathrm{~nm}$ after irradiation of t-St incorporated in ZSM-5 nanocrystals, nanosheets and nanosponges. The concentration values were extracted by data processing of the experimental absorption decays. The solid lines represent the best calculated decays using the Albery function. 
a. t-St adsorption

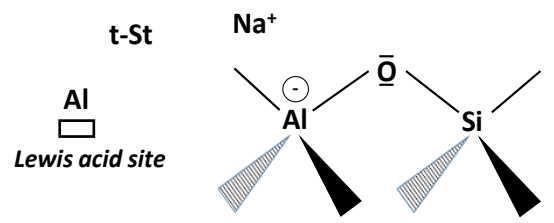

c. Direct t-St ${ }^{\bullet+}$ recombination

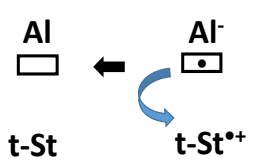

e. CTC formation

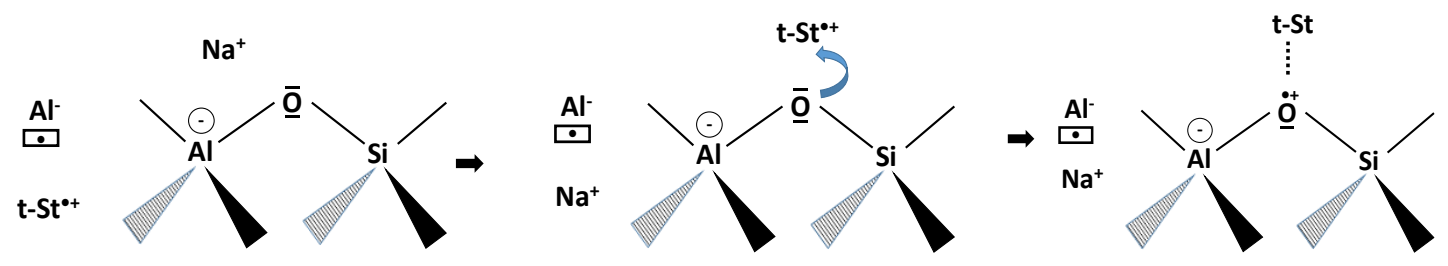

\section{f. Electron hopping}
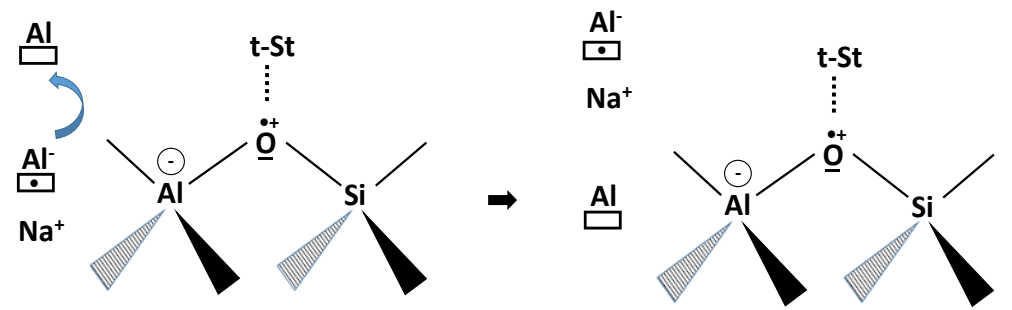

g. Final CTC recombination
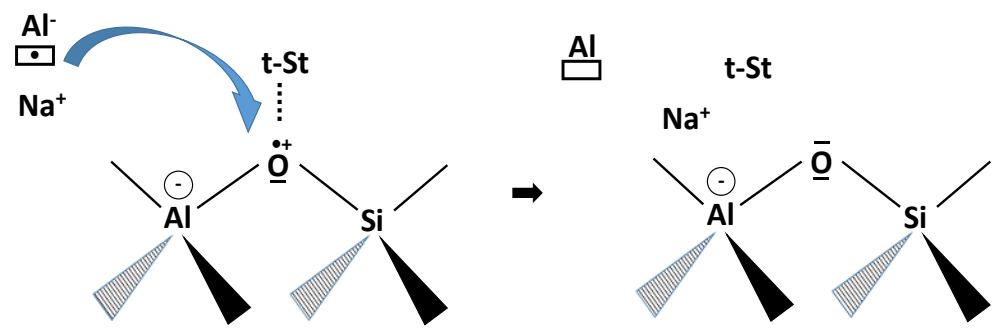

Figure 8 : Electronic transfer mechanism occurring after t-stilbene adsorption on NaZSM-5 zeolite 